\title{
Corrigendum
}

\section{Not all dietary diversity scores can legitimately be interpreted as proxies of diet quality - CORRIGENDUM}

\author{
Eric Verger, Marie-Claude Dop and Yves Martin-Prevel
}

First published online 10 April 2017

DOI: https://doi.org/10.1017/S1368980016003402. Published online by Cambridge University Press, 20 December 2016

In the above paper, the authors name Koppmair was misspelt. The sentences:

We read with great interest the recently published article 'Farm production, market access and dietary diversity in Malawi' by Koopmair and colleagues.

In their study, Koopmair and colleagues collected $24 \mathrm{~h}$ dietary recall data of household 12 members combined, as well as of individual children below the age of 5 years and of their mothers

Should have read:

We read with great interest the recently published article 'Farm production, market access and dietary diversity in Malawi' by Koppmair and colleagues.

In their study, Koppmair and colleagues collected $24 \mathrm{~h}$ dietary recall data of household 12 members combined, as well as of individual children below the age of 5 years and of their mothers

\section{Reference}

Verger E, Dop MC \& Martin-Prevel Y. Not all dietary diversity scores can legitimately be interpreted as proxies of diet quality. Public Health Nutrition, Cambridge University Press, doi.org/ 10.1017/S1368980016003402. 